\title{
Production of hydrogen and methane from wastewater sludge using anaerobic fermentation
}

\author{
C.H. Ting, D.J. Lee* \\ Department of Chemical Engineering, National Taiwan University, Taipei, Taiwan
}

Accepted 30 June 2006

Available online 30 August 2006

\begin{abstract}
Hydrogen and methane were produced from wastewater sludge using a clostridium strain. The original sludge and pre-treated (acidified, basified and freeze/thawed) sludges were the testing samples. Some pre-treatments enhanced hydrogen yield, whereas other treatments enhanced methane yield. Hydrogen fermentation can be used as a pre-stage to improve subsequent methane production from wastewater sludge.

(C) 2006 Published by Elsevier Ltd on behalf of the International Association for Hydrogen Energy.
\end{abstract}

Keywords: Anaerobic digestion; Hydrogen; Methane; Clostridium; Pre-treatment

\section{Introduction}

Hydrogen is a clean energy source. Bio-conversion of biomass to generate hydrogen has been achieved using anaerobic fermentation of some well-defined materials, in wastewater [1-4]. Limited data on hydrogen yielded from wastewater sludge have been presented at conferences [5,6].

Wang et al. [7], who performed the first systematic examination of hydrogen generated from wastewater sludge, attained a high hydrogen yield from wastewater sludge utilizing a clostridium strain isolated from the sludge sample. Later, Wang et al. [8] asserted that applying sludge filtrate produces more hydrogen than that obtained with whole sludge. Although these studies successfully established the feasibility of producing hydrogen from wastewater sludge, the hydrogen generated during the first $16-24 \mathrm{~h}$ of fermentation was consumed during a later stage. Wang et al. [7] suppressed the methanogenic pathway using various pre-treatment methods. However, most of the generated hydrogen was consumed. The pathway of hydrogen consumption, which remains unknown, is of academic and practical interest [9]. Wang et al. [10] isolated the clostridium species, the strain that effectively yields hydrogen from wastewater sludge, using a polymerase chain reaction (PCR) and 16S DNA sequence analysis.

The residual liquor remaining after hydrogen fermentation contains substantial amounts of organic substances. Ting et al. [11] demonstrated that sequential production of hydrogen and methane is an ideal solution to extracting energy and removing pollutants from wastewater sludges. In their preliminary study, specific pre-treatments improved hydrogen yield, whereas others reduced the hydrogen yield from fermented sludge. However, the mechanisms of these pre-treatments were not reported.

This study examined anaerobic fermentation of wastewater sludge, both original and pre-treated, by observing alterations in hydrogen and methane content utilizing a clostridium strain. The pre-treatments were studied to demonstrate their effects to promote hydrogen production. The metabolized products were also assessed to gain insight into the utility of sequential production of hydrogen and methane from wastewater sludge. The original and pre-treated (acidified, freeze/thawed, and basified) wastewater sludges were tested.

\section{Experimental}

Activated wastewater sludge was extracted from a wastewater treatment plant owned by the Presidential Enterprise Corp.,

* Corresponding author. Tel.: +88622362 5632; fax: +886223623040.

E-mail address: djlee@ntu.edu.tw (D.J. Lee). 
Taiwan. This plant treats 250 tons per day of food-processing wastewater using primary, secondary and tertiary treatments. The sludge $\mathrm{pH}$ was roughly 6.84 . Chemical oxygen demand (COD) for the sludge and filtrate (through a $0.45-\mu \mathrm{m}$ membrane) was $16,000 \mathrm{mg} \mathrm{l}^{-1}$ (total COD) and $86.7 \mathrm{mg} \mathrm{l}^{-1}$ (soluble COD), respectively, as determined by spectrometry (DR/2000, $\mathrm{HACH}, \mathrm{USA})$. The elemental composition of the dried samples determined using an elemental analyzer (2400, Perkin-Elmer, Boston, USA) was as follows: $\mathrm{C}, 41.3 \%$;, $6.6 \%$; and, N, $5.4 \%$. Ammonium nitrogen $\left(\mathrm{NH}_{3}-\mathrm{N}\right)$ concentration was measured by mixing a sample with Nessler reagents and scanned at $425 \mathrm{~nm}$ with a spectrophotometer (DR/2500, HACH, USA).

Original sludge was subjected to three pre-treatments (acidification, basification, and freezing and thawing) to release insoluble organic matter and deactivate methanogenic bacteria in the sludge. During acidification, perchloric acid $\left(\mathrm{HClO}_{4}\right)$ was mixed with the sludge sample for $10 \mathrm{~min}$ to obtain a sludge $\mathrm{pH}$ of 3 . Then, the sample was stored at $4{ }^{\circ} \mathrm{C}$ for $2 \mathrm{~h}$ [12]. During basification, sodium hydroxide $(\mathrm{NaOH})$ solution was mixed with sludge for $10 \mathrm{~min}$ to obtain a $\mathrm{pH}$ of 11 . The sample was stored at $4{ }^{\circ} \mathrm{C}$ for $2 \mathrm{~h}$. During the freezing and thawing pretreatment, the sludge was frozen at $-17^{\circ} \mathrm{C}$ for $24 \mathrm{~h}$ in a freezer and then thawed for $12 \mathrm{~h}$ in a water bath at $30^{\circ} \mathrm{C}$ [13].

Batch fermentation tests were performed in $125-\mathrm{ml}$ serum bottles. The clostridium strain was incubated in clostridial reinforced medium (OXOID) for 7 days prior to use. In each bottle, 45-ml of substrate, original or pre-treated sludge, was combined with 5-ml of inoculum and anaerobically incubated at $30^{\circ} \mathrm{C}$ without stirring or adding nutrients. The bottles were capped with butyl rubber stoppers and wrapped in aluminum foil to eliminate substrate photolysis. Gas and liquor samples were collected at $8,16,24,32,40,48,72$, $96,120,144,168,196,216,240,264,288,336,384,432$, and $480 \mathrm{~h}$ of digestion. Gas and liquid composition was measured for each substrate at each time point. Following gas measurements, samples were abandoned to prevent possible errors, such as gas leakage, associated with the sampling procedure.

A gas chromatography (GC-8A, Shimadzu, Japan) equipped with a stainless column packed with Porapack Q (50/80 mesh) at $70{ }^{\circ} \mathrm{C}$ and a thermal conductivity detector (TCD) were utilized to determine the hydrogen and methane concentrations in the gas phase. The GC injector and detector temperature was $100^{\circ} \mathrm{C}$. Nitrogen, used as the carrying gas, had a flow rate of $20 \mathrm{ml} \mathrm{min}^{-1}$. An integrator (HP3396 Series II, HewlettPackard, USA) was employed to integrate the peak area of the effluent curve and measure gas concentrations. Repeated measurements demonstrated that the hydrogen and methane contents had maximum relative errors of $15 \%$ and $10 \%$, respectively. The hydrogen content in the anaerobic glove box was also measured. Volatile fatty acids (VFAs) were measured with a high performance liquid chromatography (HPLC) (Ecom LCP 4100 Pump, LCD 2083 Detector, ECOM, Czech Rep.) with the mobile phase at $0.1 \%$ phosphoric acid at $0.5 \mathrm{ml} \mathrm{min}^{-1}$. The C18 column was used, and the absorption peaks at UV $210 \mathrm{~nm}$ were recorded and analyzed with Peak-ABC software (ECOM, Czech Rep.).

\section{Results and discussion}

\subsection{Sludge pre-treatment}

Before inoculum was added, the $\mathrm{pH}$ of original, acidified, basified, and freeze/thawed samples was 6.84, 3.71, 9.62, and 6.78, respectively. The corresponding soluble COD and $\mathrm{NH}_{3}-\mathrm{N}$ were $72,180,642$, and $364 \mathrm{mgl}^{-1}$, and $2.5,6.3$, 6.3 and $7.5 \mathrm{mgl}^{-1}$, respectively. Therefore, the capability of pre-treatment methods to dissolve organic substances was as follows: basification $>$ freeze-thaw $>$ acidification. The pretreatments only hydrolyzed a limited amount of proteins to produce $\mathrm{NH}_{3}-\mathrm{N}$.

Fig. 1 displays the HPLC chromatograms for the original and pre-treated sludge filtrates (prior to the digestion test). Correlation with the high SCOD results demonstrated that many peaks existed on the chromatogram of the basified sample. Product distributions in the acidified sample differed from those for basified and freeze-thawed samples.

\subsection{Biogas production}

Fig. 2 presents how the selected strain produces biogas from the clostridial-reinforced medium. After a lag time of approximately $16 \mathrm{~h}$, hydrogen content increased over time, and stabilized at $t>40 \mathrm{~h}$. The clostridium strain produced no methane. The suspension $\mathrm{pH}$ was 5.0-5.4, which is suitable for acidogenic bacterial growth.

Fig. 3 presents the hydrogen content for the original sludge with and without inoculum. Hydrogen content reduced monotonically over time and was completely consumed within $72 \mathrm{~h}$ (with no inoculum). Methane was produced starting at $140 \mathrm{~h}$ and reached $21 \mathrm{~g} \mathrm{~kg}^{-1}$ of dried solids (DS) at $t=480 \mathrm{~h}$.

With inoculum, conversely, hydrogen formed with no lag time, and its content peaked at $t=16 \mathrm{~h}$ of $0.67 \mathrm{~g} \mathrm{~kg}^{-1} \mathrm{DS}$. Afterward, hydrogen content declined over time, and was completely exhausted at $t=72 \mathrm{~h}$. The corresponding methane content increased starting at $96 \mathrm{~h}$, and yielded $131 \mathrm{~g} \mathrm{~kg}^{-1} \mathrm{DS}$ at $t=480 \mathrm{~h}$.

\subsection{Biogas production from pre-treated sludges}

Fig. 3 shows the hydrogen content in the gas phase for digested sludges pre-treated with acidification, basification, and freezing and thawing. The hydrogen content first increased then decreased when pre-treated sludges were fermented with inoculum. The hydrogen content was $0.72 \mathrm{~g} \mathrm{~kg}^{-1} \mathrm{DS}$ for the freeze/thawed sludge. Conversely, basification did not improve hydrogen production. Hydrogen content produced by the acidified sample peaked twice at $t=24-32 \mathrm{~h}$ and at $t=96-148 \mathrm{~h}$; the second peak reached $1.44 \mathrm{~g} \mathrm{~kg}^{-1} \mathrm{DS}$, the highest among the samples tested.

During the hydrogen consumption or production-consumption stages $(t<72-100 \mathrm{~h}$ except for acidified sludge), the amount of methane produced was negligible (Fig. 3b). At that time, $\mathrm{NH}_{3}-\mathrm{N}$ was largely produced (Fig. 3c). Since only a 


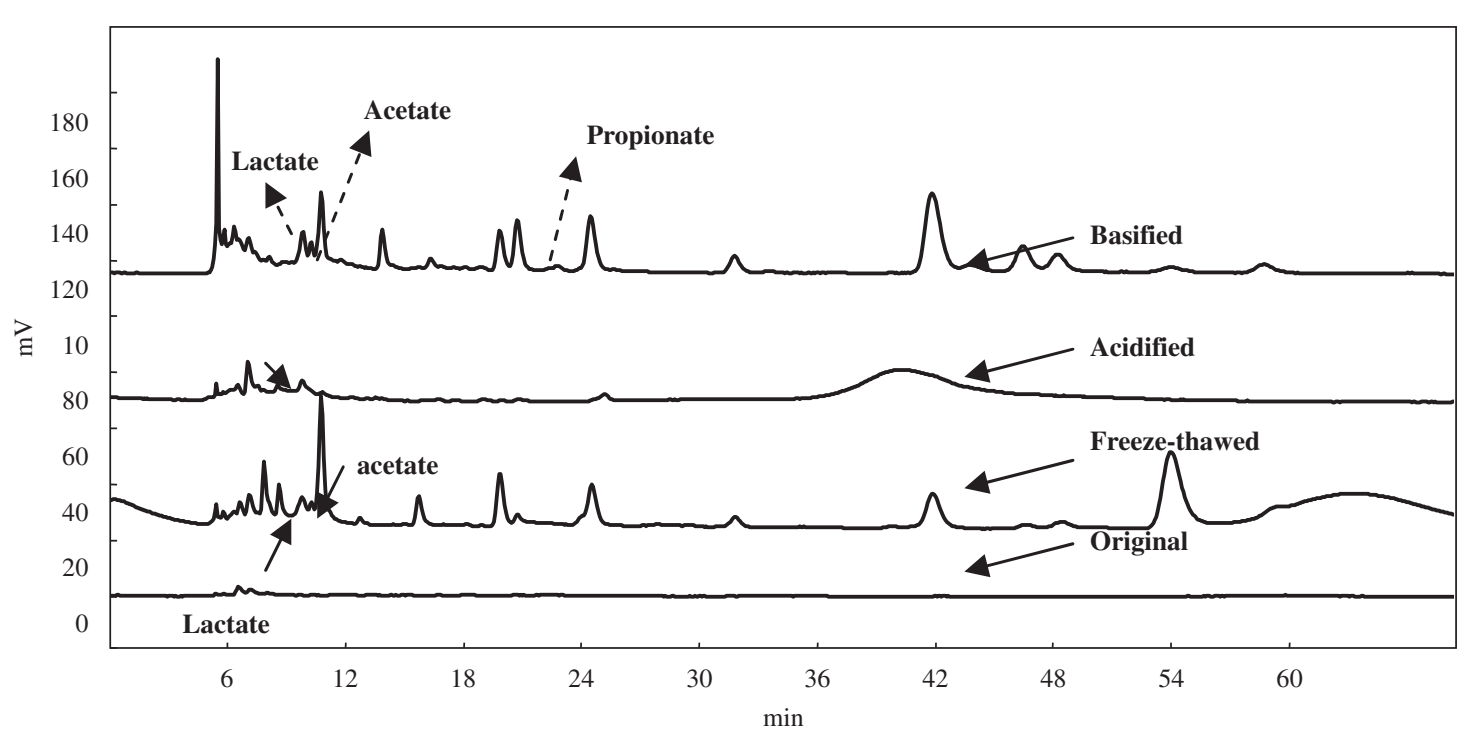

Fig. 1. The HPLC chromatograms for filtrates of original and pre-treated sludges.

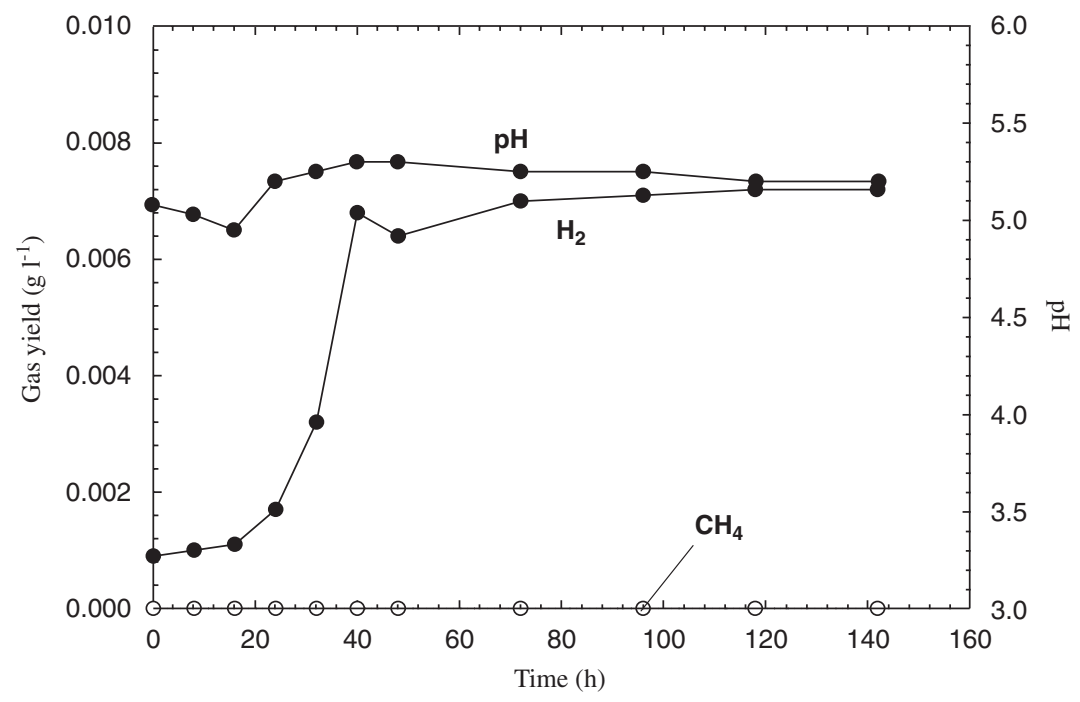

Fig. 2. Fermentation of reinforced medium using the selected strain.

small proportion of organic matter was converted to metabolites during this initial stage, the residual liquor may be suitable for methane production. The methane contents increased monotonically over time starting at roughly $100 \mathrm{~h}$. The amount of methane produced by the sludges at $184 \mathrm{~h}$ was in the following order: basified $>$ original $>$ freeze $/$ thawed $>$ original (without inoculum) $>$ acidified sludge. That is, basification promoted methane production, and reduced hydrogen production. Freezing and thawing generated a modest amount of hydrogen yield (Fig. 3a), and an adequate amount of methane during $t=250-320 \mathrm{~h}$.

Fig. $3 \mathrm{~d}$ presents the suspension $\mathrm{pH}$ in digestion tests. Hydrogen formed when $\mathrm{pH}$ was 4.5-6.0, and its production or consumption correlated with increases or decreases in $\mathrm{pH}$. Methanogenic reactions occurred at $\mathrm{pH}>5.7$, with acetate consumed first, followed by butyrate.
Experimental results (Figs. 2 and 3) indicated that although the inoculum strain produced hydrogen, microorganisms in the sludge quickly consumed the hydrogen. Most studies utilized purified, sterilized substrates to yield bio-hydrogen. The intense competition among microorganisms in the original sludge is the principal obstacle producing hydrogen from real waste streams. Additionally, more methane was generated by the inoculumdosed sludge than original sludge, even though the inoculum strain cannot produce methane (Fig. 2).

\subsection{Metabolites}

The HPLC chromatograms for original sludge (with no inoculum) demonstrated that acetate and propionate were the principal metabolites during fermentation (Fig. 4a). Over the entire test, propionate concentration increased continuously. 

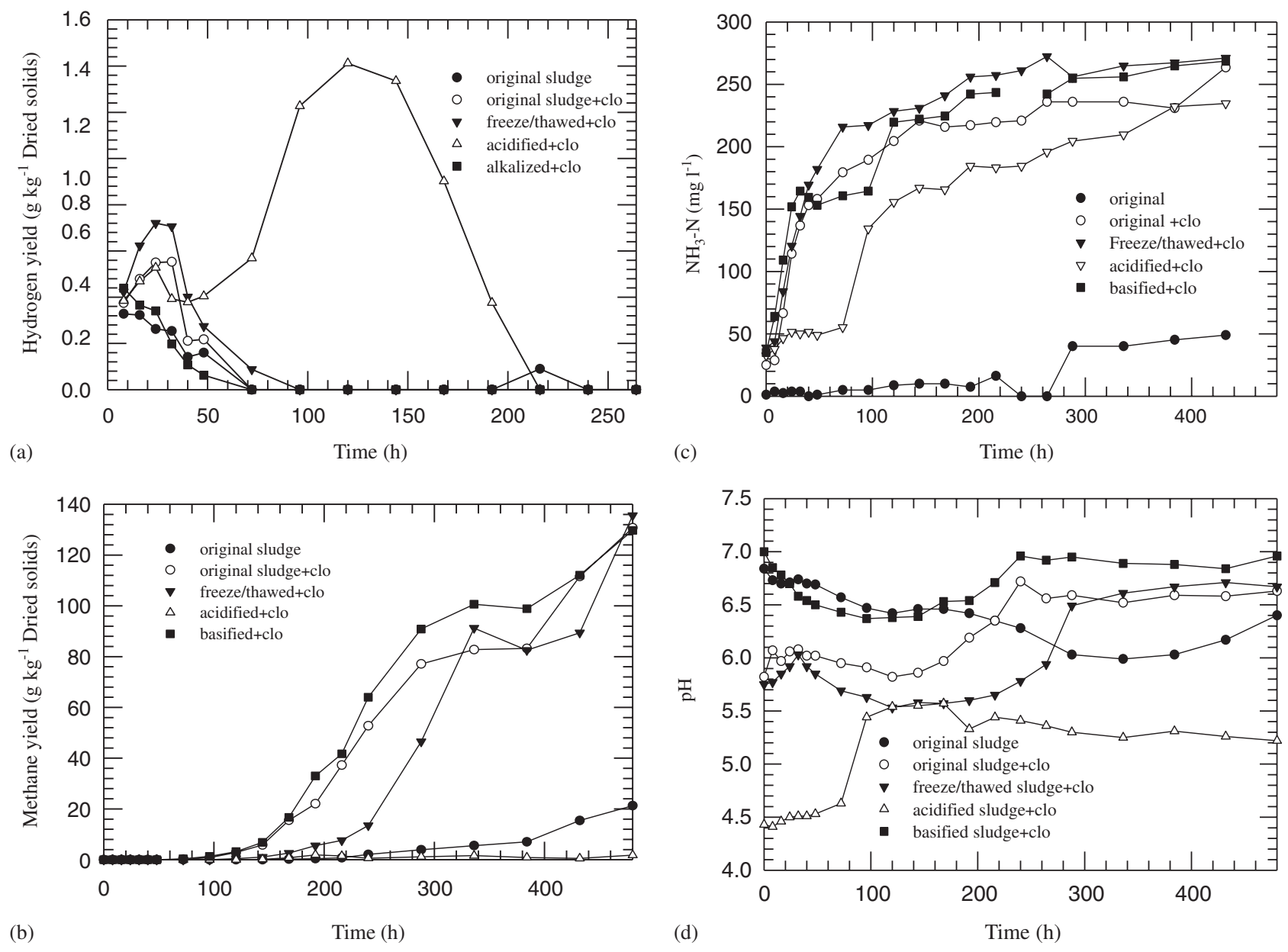

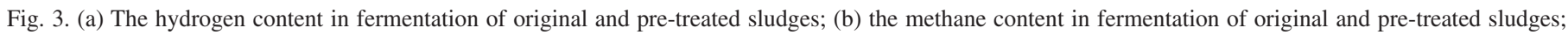
(c) the ammonium-nitrogen content in fermentation of original and pre-treated sludges; (d) the pH of suspensions in sludge digestion.

At $t<60 \mathrm{~h}$, when hydrogen was continuously consumed, $\mathrm{pH}$ dropped from 7.0 to 6.7. Subsequently, the acetate concentration increased in at $t=100-284 \mathrm{~h}$. Afterward, the acetate concentration stabilized and a small amount of methane started forming.

When inoculum was added, the metabolite distributions changed accordingly (Fig. 4b). Within $40 \mathrm{~h}$ of fermentation when hydrogen was generated and then consumed (Fig. 3a), lactate was first consumed, with VFAs forming in the following order: acetate $>$ propionate $>$ butyrate. Then, VFA concentrations increased gradually until $t=140 \mathrm{~h}$, at which time the acetate concentration started declining and was negatively correlated with the significant methane production (Fig. 3b). At $t=360 \mathrm{~h}$, the butyrate concentration started declining. Initiation of the methanogenic phase increased suspension $\mathrm{pH}$, which reached $6.6-6.8$ at $t>240 \mathrm{~h}$ (Fig. 3d), and had no correlation with $\mathrm{NH}_{3}-\mathrm{N}$ concentration (Fig. 3c).

Although the initial $\mathrm{pH}$ of the basified sample (7.0) was higher than those for freeze/thawed and acidified pretreatments (roughly 5.8) (Fig. 3c), the changes of metabolites for freeze/thawed and basified samples (Figs. 4c and d) were similar to that for original sludge with inoculum (Fig. 4b). Restated, during the fermentation test, lactate was consumed first, then VFA production was followed by acetate $>$ propionate $>$ butyrate; the VFAs were then consumed by acetate $\rightarrow$ butyrate $\rightarrow$ propionate during methane production. The nearly neutral, initial $\mathrm{pH}$ of the basified sample suspension limited the production of hydrogen at $t<40 \mathrm{~h}$, and triggered early methane production at $t>140 \mathrm{~h}$. However, the low $\mathrm{pH}$ reached by freezing/thawing sludge at $t=120 \mathrm{~h}(5.5)$ suppressed methane production up to $t=240 \mathrm{~h}$ (Fig. 3d).

The time evolution of metabolites in the acidified sample (Fig. 4e) followed a different pattern than that for other samples. Initially, the $\mathrm{pH}$ of the suspension was 4.5 . While hydrogen was produced and consumed during the first stage at $t<40 \mathrm{~h}$ (Fig. 3a), lactate was also produced and consumed in parallel and the $\mathrm{pH}$ remained relatively stable. At $t=72-96 \mathrm{~h}$, $\mathrm{pH}$ rapidly increased to roughly 5.5 , then a second stage of hydrogen production and consumption occurred $(t=96-200 \mathrm{~h})$. The corresponding concentrations of acetate and propionate increased minimally during this period; however, the $\mathrm{pH}$ of the suspension was unchanged. At $t>260 \mathrm{~h}$ butyrate was produced in substantial amounts. The corresponding $\mathrm{pH}$ of 

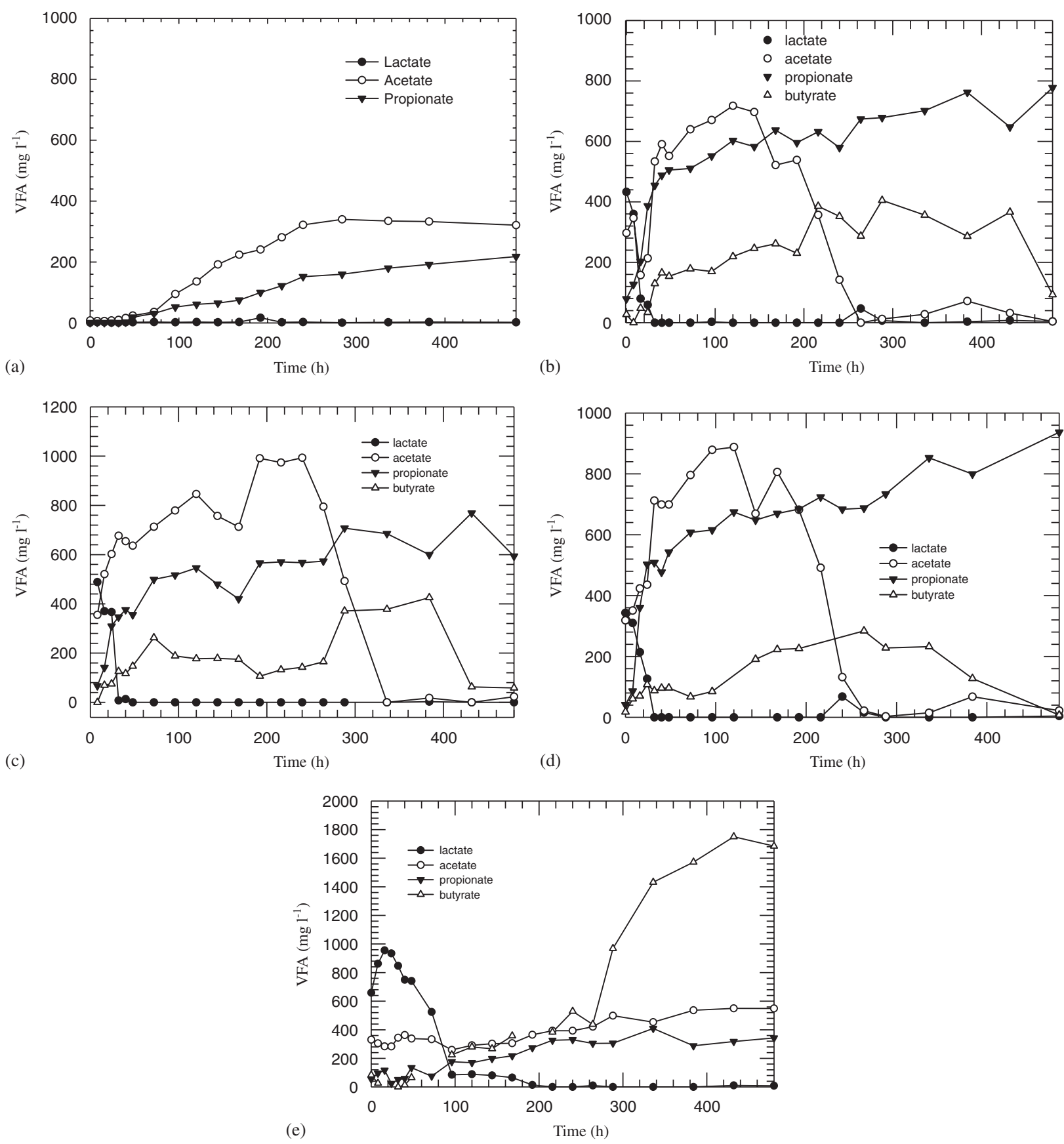

Fig. 4. Time evolutions of metabolite concentrations during anaerobic digestion. (a) Original sludge only; (b) original sludge with inoculum; (c) freeze/thawed sludge with inoculum; (d) basified sludge with inoculum; (e) acidified sludge with inoculum.

the suspension decreased only slightly. No methane was measured for the acidified sample, as the $\mathrm{pH}$ was $<5.5$ throughout the entire test.

\subsection{Sequential processes}

The data in Fig. 3 indicated that the sludge following hydrogen fermentation was more easily digested than the unfermented sample that produced methane. For example, the original sludge only produce $21 \mathrm{~g} \mathrm{CH}_{4} \mathrm{~g}^{-1} \mathrm{DS}$ at $480 \mathrm{~h}$, at the same time the original sample with a hydrogen fermentation stage yielded $125 \mathrm{~g} \mathrm{CH}_{4} \mathrm{~g}^{-1} \mathrm{DS}$, a $500 \%$ improvement. This finding is likely attributable to a marked amount of acetate generated during the hydrogen fermentation stage, suggesting that the products metabolized by fermentation enhance methane production. Wang et al. [14] proposed that a sequential process exists that simultaneously generates hydrogen and methane in separate reactors. Nevertheless, the data in Fig. 4 also demonstrated that some metabolized products are not effective at the subsequent methane production stage. Optimizing 
the hydrogen-methane process should focus on developing a method that maximizes hydrogen and methane production, and minimizes production of un-used byproducts.

\section{Conclusions}

Hydrogen and methane production during anaerobic fermentation of wastewater sludge was examined in this work. Original and pre-treated (acidified, basified, and freeze/thawed) wastewater sludges were tested. The specific quantity of hydrogen produced from original sludge (with inoculum), freeze/thawed, and acidified samples followed an increasing-decreasing pattern. The acidified sample had two distinct hydrogen production stages. Conversely, original and basified samples only consumed hydrogen.

In the subsequent methanogenesis stage, methane was produced in decreasing order by basified $>$ original $>$ frozen/ thawed $>$ original (without inoculum) $>$ acidified sludge at $184 \mathrm{~h}$, suggesting that pre-treated and/or fermented liquor is more readily to produce methane than is the original sludge. Acetate followed by butyrate was consumed during methane production. Experimental results suggest that two reactors used in a series to produce hydrogen and methane from wastewater sludge is feasible.

\section{References}

[1] Lin CY, Chang RC. Hydrogen production during the anaerobic acidogenic conversion of glucose. J Chem Technol Biotechnol 1999;74(6):498-500.

[2] Lay JJ. Modeling and optimization of anaerobic digested sludge converting starch to hydrogen. Biotechnol Bioeng 2000;68(3):269-78.
[3] Bai MD, Cheng SS, Tseng TC. Biohydrogen produced due to peptone degradation by pretreated seed sludge. Proceedings of the IWA Asia-Pacific regional conference (WaterQual 2001), Fukuoka, Japan; 2001.

[4] Lay JJ. Biohydrogen generation by mesophilic anaerobic fermentation of microcrystalline cellulose. Biotechnol Bioeng 2001;74(4):280-7.

[5] Huang CS, Lin CY, Tsai YY, Shieh YG. Preliminary study of anaerobic hydrogen production using various substrates and incubation methods. Proceedings of the 25th wastewater technical conference, Yunlin, Taiwan; 2000.

[6] Cheng SS, Bai MD, Chang SM, Wu KL, Chen WC. Studies on the feasibility of hydrogen production hydrolyzed sludge by anaerobic microorganisms. Proceedings of the 25th wastewater technical conference, Yunlin, Taiwan; 2000.

[7] Wang CC, Chang CW, Chu CP, Lee DJ, Chang BV, Liao CS. Producing hydrogen from wastewater sludge by clostridium bifermentans. J Biotechnol 2003;102(1):83-92.

[8] Wang CC, Chang CW, Chu CP, Lee DJ, Chang BV, Liao CS, et al. Using filtrate to produce bio-hydrogen by anaerobic fermentation. Water Res 2003;37(11):2789-93.

[9] Wang CC, Chang CW, Chu CP, Lee DJ, Chang BV, Liao CS. Producing hydrogen from wastewater sludge using a clostridium strain. J Environ Sci Health A 2003;38(9):1867-75.

[10] Wang CC, Chang CW, Chu CP, Lee DJ, Chang BV, Liao CS. Efficient production of hydrogen from wastewater sludge. J Chem Technol Biotechnol 2004;79(4):426-7.

[11] Ting CH, Lin KR, Lee DJ, Tay JH. Production of hydrogen and methane from wastewater sludge using anaerobic fermentation. Water Sci Technol 2004;50(9):223-8.

[12] Jean DS, Chang BV, Liao GS, Tsou GW, Lee DJ. Reduction of microbial density level in sewage sludge through $\mathrm{pH}$ adjustment and ultrasonic treatment. Water Sci Technol 2000;42(9):97-102.

[13] Hung WT, Feng WH, Tsai IH, Lee DJ, Hong SG. Uni-directional freezing of waste activated sludge: vertical freezing versus radial freezing. Water Res 1997;31(9):2219-28.

[14] Wang CC, Chang CW, Chu CP, Lee DJ, Chang BV. Sequential production of hydrogen and methane from wastewater sludge using anaerobic fermentation. J Chin Inst Chem Eng 2003;34(6):683-8. 